\title{
DNA methylation and temperature stress in an Antarctic polychaete, Spiophanes tcherniai
}

\author{
Adam G. Marsh ${ }^{1 *}$ and Annamarie A. Pasqualone ${ }^{2}$ \\ ${ }^{1}$ Center for Bioinformatics and Computational Biology, School of Marine Science and Policy, University of Delaware, Lewes, DE, USA \\ ${ }^{2}$ Marine Bioscience, School of Marine Science and Policy, University of Delaware, Lewes, DE, USA
}

\section{Edited by:}

Mackenzie Gavery, University of Washington, USA

Reviewed by:

David Rivers, Loyola University

Maryland, USA

Solenn Patalano, The Babraham Institute - BBSRC, UK

Mauricio Rodriguez-Lanetty, Florida International University, USA

*Correspondence:

Adam G. Marsh, Center for Bioinformatics and Computational

Biology, School Marine Science and

Policy, University of Delaware, 700

Pilottown Road, Smith Laboratory

114, Lewes, DE, 19958, USA

e-mail: amarsh@udel.edu
Epigenetic modifications of DNA and histones are a primary mechanism by which gene expression activities may be modified in response to environmental stimuli. Here we characterize patterns of methyl-cytosine composition in the marine polychaete Spiophanes tcherniai from McMurdo Sound, Antarctica. We cultured adult worms at two temperatures, $-1.5^{\circ} \mathrm{C}$ (ambient control) and $+4^{\circ} \mathrm{C}$ (warm treatment), for 4 weeks. We observed a rapid capacity for $S$. tcherniai organismal respiration rates and underlying catalytic rates of citrate synthase at $+4^{\circ} \mathrm{C}$ to return to control levels in less than 4 weeks. We profiled changes in the methylation states of $\mathrm{CpG}$ sites in these treatments using an NGS strategy to computationally reconstruct and quantify methylation status across the genome. In our analysis we recovered $120,000 \mathrm{CpG}$ sites in assembled contigs from both treatments. Of those, we were able to align $28,000 \mathrm{CpG}$ sites in common between the two sample groups. In comparing these aligned sites between treatments, only 3000 (11\%) evidenced a change in methylation state, but over $85 \%$ of changes involved a gain of a 5-methyl group on a $\mathrm{CpG}$ site (net increase in methyation). The ability to score $\mathrm{CpG}$ sites as partially methylated among gDNA copies in a sample opens up a new avenue for assessing DNA methylation responses to changing environments. By quantitatively distinguishing a "mixed" population of copies of one CpG site, we can begin to identify dynamic, non-binary, continuous-response reactions in DNA methylation intensity or density that previously may have been overlooked as noise.

Keywords: epigenetics, DNA methylation, cold acclimation, polychaete, energy metabolism, Antarctica

\section{INTRODUCTION}

The emergent field of environmental epigenetics broadly encompasses all heritable changes in gene function and expression that are not associated with a change in underlying genomic DNA sequences (Ho and Burggren, 2010). The epigenome itself represents a dynamic system of chemical controls that impact gene expression at a molecular level (Jaenisch and Bird, 2003). DNA methylation is a primary component of the epigenome and involves the covalent bonding of a methyl group $\left(\mathrm{CH}_{3}\right)$ to the carbon 5 position of a cytosine ring, which forms 5 -methyl-cytosine (Feil, 2006).

Unlike the underlying genome which remains largely static across cell types and throughout the course of an individual's lifespan, the methylome is a dynamic system that is influenced by both intrinsic and external environmental signals (Wolffe and Matzke, 1999). Epigenetic modifications of DNA represent an important mechanism through which organisms are able to quickly adjust gene expression in response to changes in environmental conditions including thermal stress. Due to the innate plasticity of DNA methylation of cytosine bases, environmental cues can induce epigenetic shifts in the timing and intensity of gene expression that may contribute to a physiological acclimation response.

Differential methylation patterns at homologous loci may result in functional epialleles that allow organisms to respond to environmental stimuli by expressing alternative phenotypes, which can include behavioral, developmental, morphological, and physiological modifications (Angers et al., 2010). These modified epigenetic profiles enable organisms to maintain performance in the context of an environmental change and facilitate short-term acclimation. A number of studies focusing on both plant and animal models have demonstrated the role of DNA methylation in coordinating the regulation of physiological processes during thermal stress through the epigenetic control of gene expression (Boyko and Kovalchuk, 2008; Pecinka et al., 2010; Correia et al., 2013). Direct correlations between environmental temperature and genome methylation have been described in fish (polar to tropical; Varriale and Bernardi, 2006a) and in temperate reptiles (Varriale and Bernardi, 2006b). Work with invertebrates has revealed the large importance that DNA methylation plays in genome evolution and environmentally driven gene expression shifts (Elango et al., 2009; Gavery and Roberts, 2010; Okamura et al., 2011; Falckenhayn et al., 2013; Glastad et al., 2013; Wang et al., 2013).

The annelid family Spionidae consists of tubicolous polychaetes that inhabit coastal marine sediments (Grube, 1860). Organisms within this genus utilize characteristic prehensile palps originating dorsolaterally from the peristomal segment for construction of individual tubes (Blake and Arnofsky, 1999). These tubes, which can reach lengths of $85 \mathrm{~mm}$ and have a hollow $2 \mathrm{~mm}$ 
diameter, are constructed of sediment that has been cemented by mucous. An ecosystem engineer, S. tcherniai populations in McMurdo Sound, Antarctica, can form dense tube mats containing over 3000 individuals per square meter (Conlan et al., 2010; Kim et al., 2010). Spiophanes tcherniai is characterized primarily as a selective deposit feeder with the capacity for secondary suspension feeding (Oliver and Slattery, 1985; Kim et al., 2010). An analysis of this species' gut constituents indicates a diet composed primarily of amorphous organic material and diatoms (Oliver and Slattery, 1985).

In coastal Antarctic waters, S. tcherniai inhabits soft sediments and has been observed from intertidal regions to depths reaching $851 \mathrm{~m}$ (Blake, 1983). Among the first species to colonize disturbed environments, this opportunistic species has been observed naturally in environments with varying degrees of physical disturbance, organic enrichment, and chemical pollution (Lenihan and Oliver, 1995; Conlan et al., 2004). The broad distribution and high local abundances of this species in a variety of benthic environments in the Southern Ocean suggest that $S$. tcherniai has a high capacity for acclimating to diverse polar habitats.

Here we identify shifts in methyl-cytosine composition within the genome of the Antarctic marine polychaete S. tcherniai in response to an increase in seawater temperature. The high latitude of McMurdo Sound, Antarctica, ( $77^{\circ} 51.063^{\prime} \mathrm{S}$ ), makes this polar sea stenothermal at $-1.86^{\circ} \mathrm{C}$, the freezing point of seawater at $32 \mathrm{psu}$. A few days each year seawater temperatures may rise above $-1.0^{\circ} \mathrm{C}$, with $-0.5^{\circ} \mathrm{C}$ being the seasonal high water temperature of recent record (Hunt et al., 2003). As global sea surface temperatures rise, polar regions are projected to evidence some of the largest changes in ecosystem structure because of their long stenothermal history (Moline et al., 2008; Schofield et al., 2010; Doney et al., 2012; Richard et al., 2012). Understanding mechanisms and capacities for surviving increasing temperatures is important in a global context of climate change in polar seas.

\section{MATERIALS AND METHODS}

\subsection{POLYCHAETE CULTURE AND TREATMENTS}

Live individuals were obtained from sediment collected by SCUBA at the Intake Jetty off of McMurdo Station $\left(77^{\circ} 51.063^{\prime} \mathrm{S}\right.$, $\left.166^{\circ} 39.867^{\prime} \mathrm{E}\right)$. Dense $S$. tcherniai tube mats cover the soft sediment around the jetty, and it is easy for divers to scoop these mats into buckets to be lifted back to the surface. The buckets were immediately transported to the McMurdo Station aquarium facility were the adult tubes could be quickly sieved from the bottom sediments under ambient $\left(-1.5^{\circ} \mathrm{C}\right)$ running seawater. The tubes were visually sorted and those containing adult worms were placed into 8 subcultures containing at least 100 individuals each. These adults were maintained at $-1.5^{\circ} \mathrm{C}$ and $32 \mathrm{ppt}$ salinity in the running seawater facility at McMurdo Station. They were fed ground Tetramin ${ }^{\circledR}$ Veggie Fish Flakes (nutritional data available in Marsh et al., 1989) once a week while held in the seawater tables for 2 weeks.

After this initial acclimation period, adult worms were transferred to $11.4 \mathrm{~L}$ plastic tubs filled with $2 \mathrm{~cm}$ fine $(<200 \mu \mathrm{m})$ sieved sediment and filtered sea water (approximately 100-200 individuals). These tubs were placed in either $-1.5^{\circ} \mathrm{C}$ or $+4^{\circ} \mathrm{C}$ walk-in environmental chambers (three replicate tubs per temperature) with gentle aeration in each. Once a week, seawater was changed in each tub, and the worms were fed 1 gram of ground Tetramin ${ }^{\circledR}$. No mortality was evident in the cultures and worms maintained normal feeding and tub building activities. Worms were maintained under these conditions for 4 weeks. Physiological rate measurements were made at 0,2 , and 4 weeks. Methylation profiling was executed on worms at the 4 week time point. Preliminary experimental work with this polychaete in previous field seasons indicated that 4 weeks at a $+4^{\circ} \mathrm{C}$ thermal stress was sufficient time for physiological rate processes to re-stabilize at control $\left(-1.5^{\circ} \mathrm{C}\right)$ levels. Thus, our time course was focused on events during this 4 week interval.

\subsection{PHYSIOLOGICAL MEASUREMENTS \\ 2.2.1. Respiration}

Fluorescence quenching of an organic ruthenium complex (Ruthenium(II)-tris-4,7-diphenyl-1,10-phenantroline perchlorate) in the presence of oxygen can be directly measured in optode devices. The application of this technique has been used for measuring small invertebrate respiration rates in a multi-well plate format (Szela and Marsh, 2005). Recently, we have been successful adding the $\mathrm{Ru}$ fluorophore directly in solution so that fluorescence efficiency is more uniform across the plate (Cowart et al., 2011). Individuals were aliquoted in $200 \mu \mathrm{l}$ seawater and overlaid with heavy mineral oil into a 96-well flat bottom untreated polystyrene plate. For each assay, several blank wells with filtered seawater were also setup. Fluorescence was measured with a microtiter plate fluorometer (FLX-800, Bio-Tek Instruments) using $485 \mathrm{~nm}$ excitation and $590 \mathrm{~nm}$ emission filter sets. Data was logged using the manufacturer's software (KC4 Ver. 2.7.8). Respiration measurements were taken over an $8 \mathrm{~h}$ period with the fluorometer inside an incubator to maintain the experimental temperature. Rate analyses were calculated from a custom perl script that formats the data output from the fluorescent reader for input into a custom $\mathrm{R}$ script to run the oxygen consumption calculation using the Stern-Volmer equation (Glazer et al., 2004). Respiration rates were normalized to total DNA measurements of each individual (PicoGreen, Molecular Probes) as a proxy for cell number.

\subsubsection{Citrate synthase}

The Kreb's cycle mitochondrial enzyme, citrate synthase, can serve as a proxy index of maximum aerobic capacity and is often considered a potentially sensitive enzymatic step for temperature adaptations (Fields et al., 2008). We used CS measurements to compare metabolic potential (citrate synthase activity) to actual rates of energy consumption, as measured by respiration. The general method for the measurement of citrate synthase is well established (Faloona and Srere, 1969), and it has been optimized for small volumes (Marsh et al., 1999; Pace et al., 2006). Briefly, worm tissues were homogenized in $100 \mu \mathrm{l}$ of $50 \mathrm{mM}$ ImidazoleĐCl ( $\mathrm{pH}$ 7.5). Standard assay conditions used $250 \mu \mathrm{M}$ DTNB (Ellman's Reagent), $500 \mu \mathrm{M}$ oxaloacetate and $400 \mu \mathrm{M}$ acetyl-coenzyme $\mathrm{A}$ in a final volume of $100 \mu \mathrm{l}$. Reaction rates were monitored at $412 \mathrm{~nm}$ in a plate-reading spectrophotometer inside an incubation chamber maintained at the experimental temperature. Imidazole is essentially the side 
group on the amino acid histidine, and it was used as the buffer because the protonation state of the amine nitrogen as a function of temperature closely parallels that of intracellular proteins (alpha-stat regulation), thereby ensuring physiologically realistic enzyme function across a broad range of temperatures (Fields et al., 2008). Substrate saturation curves were run to ensure $V_{\max }$ reaction rates were measured. Net reaction rates were calculated with a least-squares linear regression analysis of absorbance against time. Citrate production is calculated from the DTNB extinction coefficient and given as pmol citrate larva ${ }^{-1} \mathrm{~min}^{-1}$.

\subsection{DNA METHYLATION}

On the 28th day of the temperature exposure, two replicates of 20 adults each were collected and pooled for genomic DNA extraction. DNA was isolated using a standard cetyl trimethyl ammonium bromide $(\mathrm{CTAB})$ protocol and purified using Qiagen's DNeasy Blood and Tissue Kit. A $10 \mu \mathrm{g}$ aliquot of the DNA was then digested with the methylation-sensitive restriction endonuclease HpaII, in a fashion following Jelinek et al. (2012). Overall, the strategy is similar to an earlier methylsensitive amplified fragment length polymorphism assay (MSAP) except that fragment detection is based on reconstruction of CpG site methylation computationally from NGS sequence read data.

Once digested, DNA was washed with Qiagen's QIAquick PCR Purification Kit and sheared to a median size of $300 \mathrm{bp}$ using the Covaris AFA technology. DNA libraries were prepared using Illumina's Genomic DNA Sample Prep Kit, and 50-cycle single-read sequencing was performed on genomic DNA libraries using Illumina's sequencing by synthesis (SBS) technology on a HiSeq2500 (Delaware Biotechnology Institute, University of Delaware).

The HiSeq sequence reads were processed using a custom bioinformatic pipeline and proprietary software platform. The workflow is managed down a decision tree from raw read QC to final graphic analysis of methylation profiling differences between the experimental treatments. The novel platform performs the following tasks: (1) quality control to filter sequence tags for a designated threshold of confidence and length, (2) isolation of informative target sequence reads, (3) sequence compression to reduce complexity, (4) contig assembly using velvet, (5) CpG quantification for methyl-cytosine site distributions, (6) methylation profiling comparison between treatment groups, and (7) output of data plots and analyses. This software platform consists of a series of python scripts optimized for distributed processing on a computer cluster. The software and algorithms are proprietary as described in the Disclosure Statement. All sequence data reported here are publicly available through the Sequence Read Archive of the US National Center for Biotechnology Information (Accession \#SRP040946) or they can be obtained by contacting the lead author.

\section{RESULTS}

\subsection{PHYSIOLOGY}

Field collection of adult worms requires scooping sediment up into buckets while SCUBA diving, returning the buckets to the lab, sieving the sediment to isolate adult worm tubes, and then transferring those tubes into fresh culture trays in running seawater. In Figure 1, the mechanical agitation from the collection and handling may be apparent in the wide variance in respiration rates that were measured on the 1st day that the experimental culture trays were setup. During the 4 week time course of the study, respiration rates in the control and the +4 treatment group were lower with reduced inter individual variance. Individual oxygen consumption rates were not statistically different at the 4 week sampling point (ANOVA, $n=23$ ).

The maximum specific activity for citrate synthase (CS) reveals a wide inter-individual variance at the onset of the experiment. Within the first 2 weeks of culturing, this variance decreases (Figure 2). There is a noticeable decrease in the mean citrate $\mathrm{V}_{\text {max }}$ at day 14 in the $-1.5^{\circ} \mathrm{C}$ control cultures, in contrast to a maintenance of the same mean levels between day 0 and 14 in the $+4^{\circ} \mathrm{C}$ cultures. This represents a temporal pattern in shifting means and variances suggestive of a temperature induced response between $-1.5^{\circ} \mathrm{C}$ and $+4^{\circ} \mathrm{C}$ cultures on day 14 . However, $\mathrm{CS} \mathrm{V}_{\max }$ treatment means were not statistically different at day 28 (ANOVA, $n=29$ ).

\subsection{BIOINFORMATICS}

Two replicate gDNA samples were processed for each temperature and sequenced in separate flow cells on the HiSeq2500. Sequence reads were first processed independently for each replicate sample, but the final analysis presented here combined the raw sequence reads from replicates and processed them together. In Table 1, informatic statistics related to the sequence analysis are presented. The assembler velvet (v1.1) was used with a $21 \mathrm{kmer}$ value (after optimization from 19 to 35 ). Note that the removal of non-informative sequence reads from the analysis results in

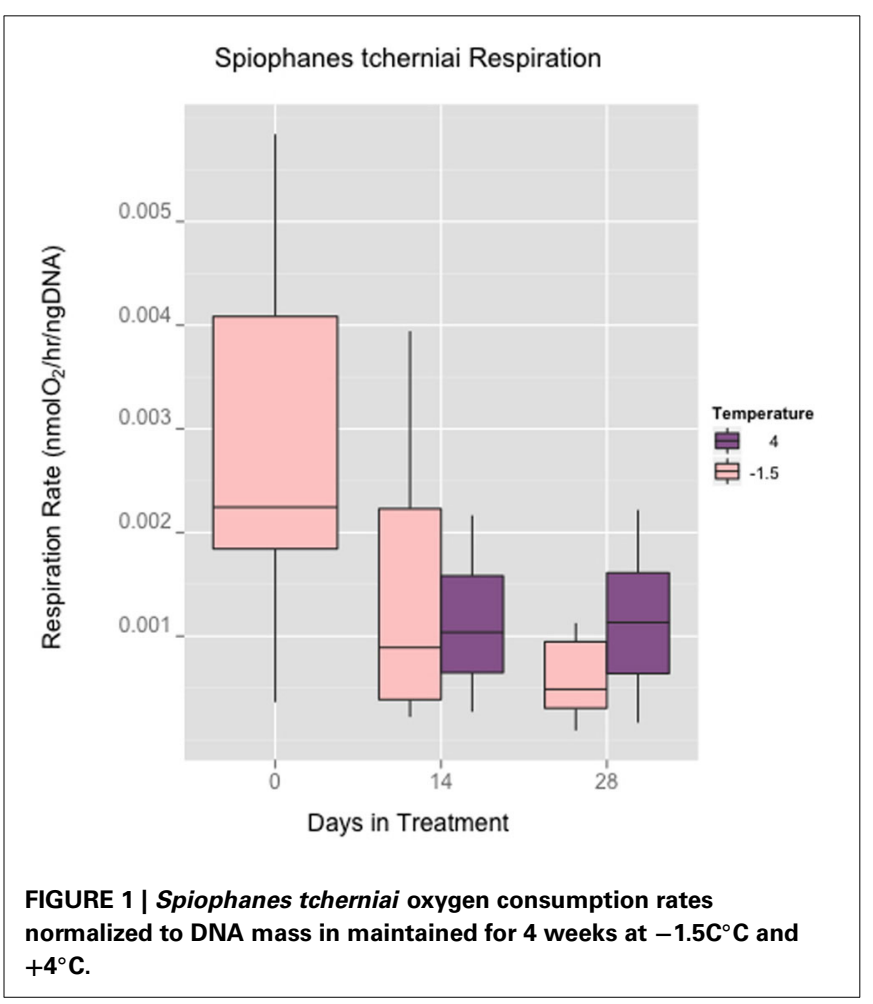




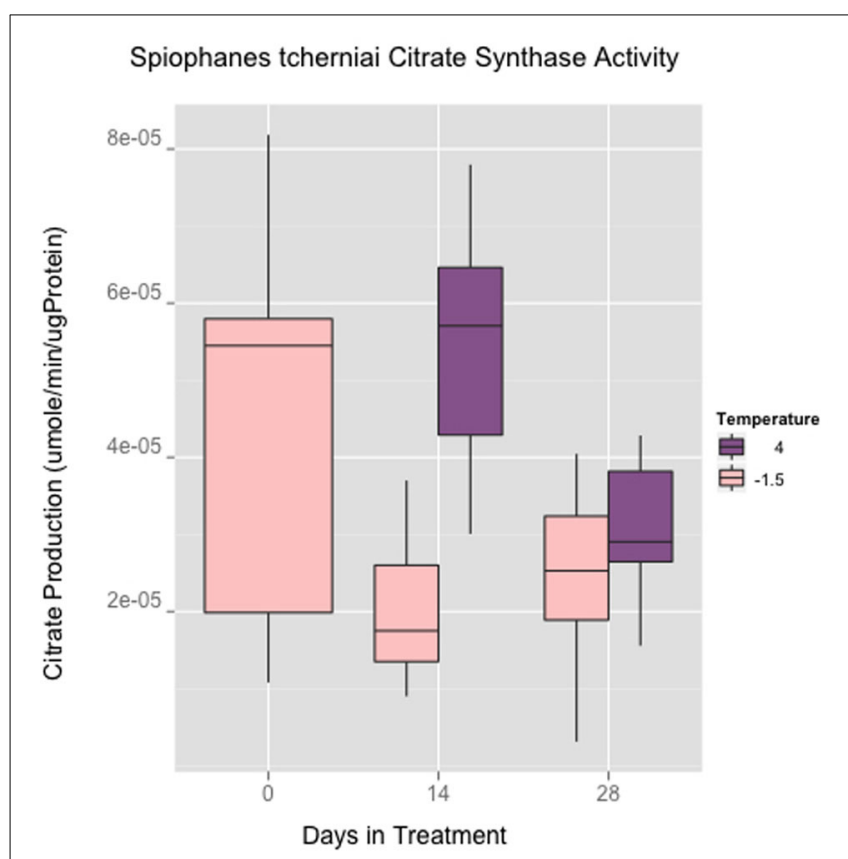

FIGURE 2 | Spiophanes tcherniai maximum catalytic rates of citrate synthase normalized to protein mass in worms maintained for 4 weeks at $-1.5^{\circ} \mathrm{C}$ and $+4^{\circ} \mathrm{C}$.

Table 1 | Sequence and assembly informatics.

\begin{tabular}{|c|c|c|}
\hline & $-1.5^{\circ} \mathrm{C}$ & $+4^{\circ} \mathrm{C}$ \\
\hline \multicolumn{3}{|l|}{ SEQUENCING } \\
\hline Total reads & 7,757,988 & 7,729,833 \\
\hline Reads assembled & $1,495,960$ & $1,567,432$ \\
\hline Assembled contigs & 493,107 & 516,081 \\
\hline Coverage & $5.72 x$ & $5.45 x$ \\
\hline Contig n50 length & 51 & 50 \\
\hline Contig max length & 469 & 279 \\
\hline \multicolumn{3}{|l|}{ CpG PROFILES } \\
\hline Total recovered CpG sites & 118,651 & 119,550 \\
\hline Methylated CpG (MET) & 105,399 & 115,910 \\
\hline Unmethylated CpG (UMT) & 6,637 & 2,282 \\
\hline Mixed CpG (MIX) & 6,475 & 1,231 \\
\hline Unkown CpG status & 140 & 129 \\
\hline CpG COMPARISON & & $-1.5^{\circ} \mathrm{C}$ vs. $4^{\circ} \mathrm{C}$ \\
\hline Matched CpG sites & & 28,626 \\
\hline Unchanged CpG status & & 25,559 \\
\hline Changed $\mathrm{CpG}$ status & & 3,067 \\
\hline
\end{tabular}

short contigs that are concentrated around $\mathrm{CpG}$ repeat domains. Thus, the assembly statistics do not match results that a normal full genomic DNA assembly would produce.

Overall, most of the $\mathrm{CpG}$ sites reconstructed in the assembled contigs were methylated: $89 \%$ and $97 \%$ in $-1.5^{\circ} \mathrm{C}$ and $+4^{\circ} \mathrm{C}$ gDNA samples, respectively. This number is not to be confused with a percent methyl-cytosine composition measurement. Here, the fraction is essentially showing $\mathrm{C}(5 \mathrm{mC}) \mathrm{GG}$ counts relative to total CCGG counts. Of the almost $120 \mathrm{k} \mathrm{CpG}$ sites recovered in the assembled contigs in each temperature, only $28 \mathrm{k} \mathrm{CpG}$ sites were matched to the same genomic contigs between treatments (23\%). Of these matched CpG sites, only 3067 (11\%) evidenced a change in methylation state between the temperature treatments. The remaining 25,559 sites did not vary (remained unchanged) after 4 weeks in different temperature regimes. All of the following CpG profile analyses are based on the 3067 sites that did change during the experiment, however, this response is limited to a discrete fraction of the total CpG sites recovered in the NGS sequence reads. About $90 \%$ of the $\mathrm{CpG}$ sites matched between the treatments had the same unchanged methylation status.

\subsection{Cpg Methylation PROfiles}

All of the CpG sites resolved in the filtered assembly have two metric score values corresponding to the relative count of methylated and unmethylated $(5 \mathrm{mC})$ scores at the internal cytosine in a "CCGG" motif. Plotting these derivative scores locates each CpG site within a 2D area associated with high methylation (most of the copies of that contig in the sample were methylated), low methylation (most of the copies of that contig in the sample were unmethylated), or equivalent methylation. Although these designations arise from the metric analysis in the $2 \mathrm{D}$ plane, at this point a qualitative review of $\mathrm{CpG}$ sites in the assembled fragments suggests greater than $75 \%$ and less than $25 \%$ boundaries for methylated and unmethylated groupings. CpG sites for which a status determination could not be made (mostly because coverage was too low, $<5 x$ ) are indicated as "Unknowns" (Figure 3). A complementary spatial distribution plot of $\mathrm{CpG}$ methylation for the $+4^{\circ} \mathrm{C}$ worms is shown in Figure 4. All of the $\mathrm{CpG}$ sites plotted in Figure 3 are also plotted in Figure 4 such that the methylation status at each $\mathrm{CpG}$ site can be compared between treatments $(n=3067)$.

If one were to overlay the two Figures 3, 4 and draw lines to connect the same CpG site in both treatments, the comparative idea would be clear, but the resulting graph would be indecipherable. In Figure 5, this idea of overlaying the $+4^{\circ} \mathrm{C}$ and $-1.5^{\circ} \mathrm{C}$ data with a line for each $\mathrm{CpG}$ site connecting its methylation state in each treatment has been simplified by pulling the data apart into six panels, one for each potential shift. These shifts are (read $x$-to-y): MET:MIX (partial methylation loss), MET:UMT (full methylation loss), MIX:MET (partial methylation gain), MIX:UMT (partial methylation loss), UMT:MET (full methylation gain), UMT:MIX (partial methylation gain).

Here, a striking difference in methylation dynamics is evident between the panels. The number of $\mathrm{CpG}$ sites that change between treatments is shown in Table 2, where the two largest shifts between $-1.5^{\circ} \mathrm{C}$ and $+4^{\circ} \mathrm{C}$ are in mixed to methylated sites and unmethylated to methylated sites. In the panel plots (Figure 5), it is important to note that the length of the line for a CpG site in a panel is indicative of the strength or weight of the methylation shift. Basically, a change from $100 \%$ of a CpG site copies being unmethylated at $-1.5^{\circ} \mathrm{C}$ and then $100 \%$ of them becoming methylated at $+4^{\circ} \mathrm{C}$ (UMT:MET) is a greater cellular response than $50 \%$ of a $\mathrm{CpG}$ site copies being unmethylated at $-1.5^{\circ} \mathrm{C}$ and then the remaining $50 \%$ become methylated at $+4^{\circ} \mathrm{C}$ (UMT:MET). In Figure 5, one can see the type of shifts that are evident and the magnitude of those shifts. The overall 


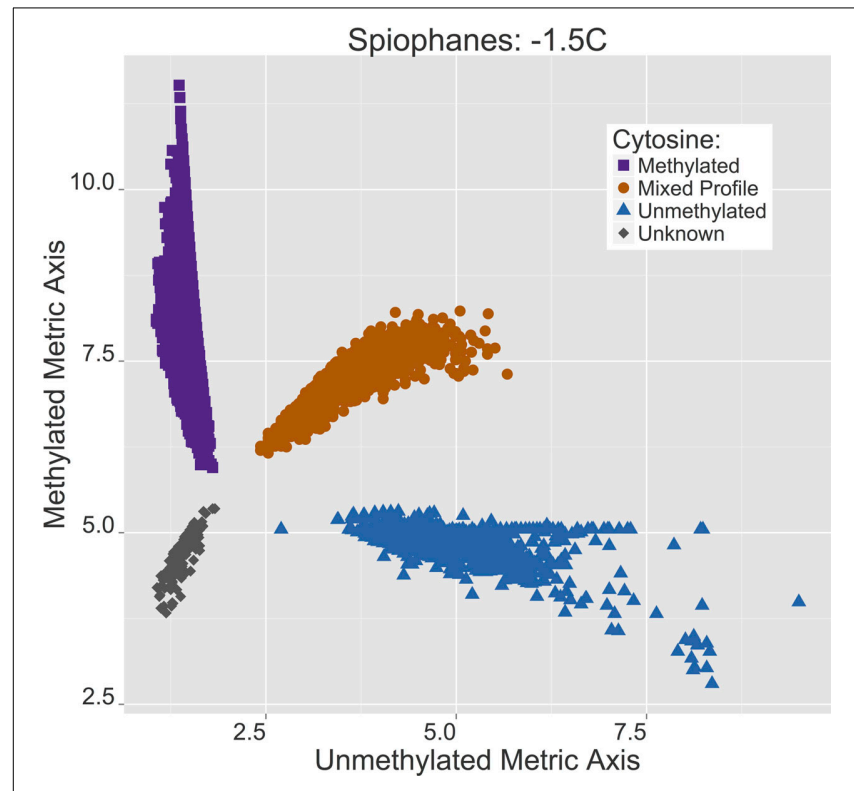

FIGURE 3 | Spiophanes tcherniai methylation score profile for the

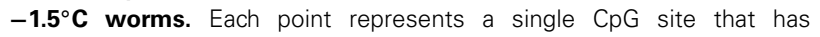
been scored for a proportional representation of methylated and non-methylated copies in these samples, with these two variables plotted on each axis. Points are divided into four groups: purple squares $=$ methylated sites, brown circles $=$ mixed methylation sites, blue triangles $=$ unmethylated sites, gray diamonds $=$ unknown or unresolved sites.

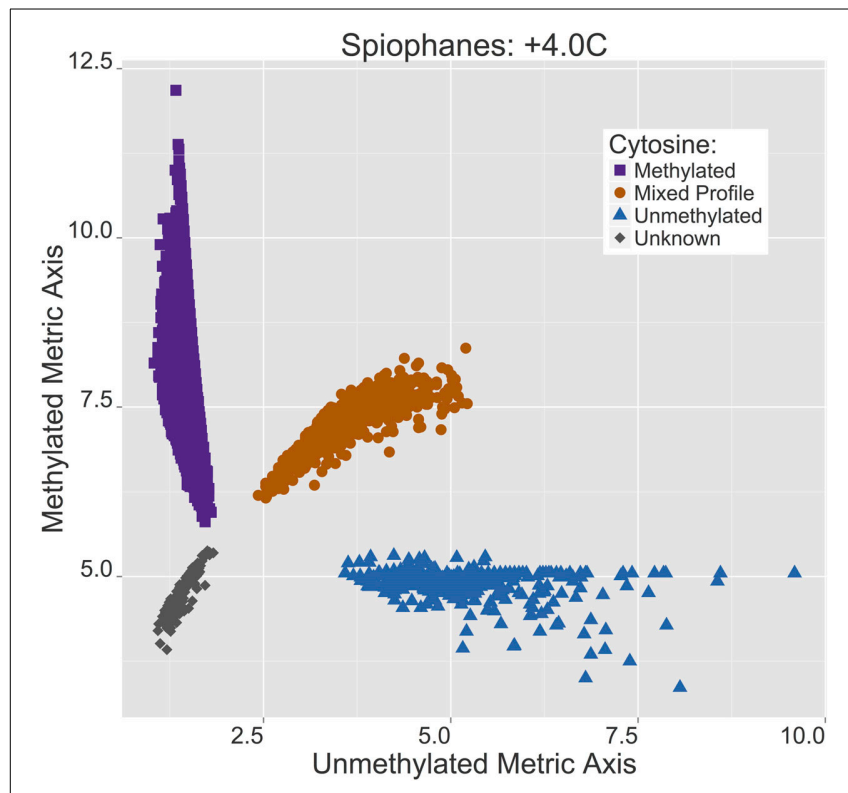

FIGURE 4 | Spiophanes tcherniai methylation score profile for the $+4^{\circ} \mathbf{C}$ worms. Each point represents a single $\mathrm{CpG}$ site that has been scored for a proportional representation of methylated and non-methylated copies in these samples, with these two variables plotted on each axis. Points are divided into four groups: purple squares $=$ methylated sites, brown circles $=$ mixed methylation sites, blue triangles = unmethylated sites, gray diamonds $=$ unknown or unresolved sites. pattern that emerges here is that there are two dominant methylation gains occurring (MIX:MET, UMT:MET), while only the partial methylation loss in MET:MIX is high in terms of number of $\mathrm{CpG}$ sites.

The length of the lines plotted for each CpG site in Figure 5 are essentially a representation of the magnitude of a methylation change across all copies of a CpG site in a sample. In Figure 6, frequency distribution plots are shown for these magnitude vectors divided into "Gain" and "Loss" processes. Overall, there is a striking difference in the "Gain" and "Loss" distributions in terms of both the numerical number of events and their magnitude. The observed counts here reveal the degree to which points and lines are plotted over one another in Figures 3, 4, and 5. The "Gain" distribution is clearly bimodal as a result of the strong Full methylation increases (Figure 5, panel UMT:MET) and the strong Partial methylation increases (Figure 5, panel MIX:MET).

The magnitude scores for each CpG site methylation change in Figure $\mathbf{6}$ can be quickly summed into "Gain" and "Loss" components, and then summed to obtain a "Net Methylation Change" (Figure 7) The worms cultured at $+4^{\circ} \mathrm{C}$ for 4 weeks demonstrably evidence a large increase (net gain) of site specific $\mathrm{CpG}$ methylation status relative to $-1.5^{\circ} \mathrm{C}$ control cultures. Of the total magnitude of observed methylation changes, $88.5 \%$ were methylation gains.

\section{DISCUSSION}

\subsection{TEMPERATURE}

The stenothermal habitat of McMurdo Sound evidences a nearly constant temperature of $-1.86^{\circ} \mathrm{C}$ throughout much of the year, with the exception of a short, seasonal increase to around $-0.5^{\circ} \mathrm{C}$ for 2-3 weeks in late austral summer (Hunt et al., 2003). In a 2 year period of continuous in situ measurements at the McMurdo intake jetty, there were only 8-21 days each year where water temperatures where above $-1.1^{\circ} \mathrm{C}$. In our experiment, we were able to maintain a $-1.5^{\circ} \mathrm{C}$ control laboratory culture temperature in early Austral spring in the McMurdo aquarium facility. The warm temperature treatment of $+4^{\circ} \mathrm{C}$ represents a temperature that $S$. tcherniai populations in the area have not been exposed to since the glaciation of the Antarctic continent, 14-20 million years ago.

The ability of $S$. tcherniai to quickly acclimate mitochondrial performance and organismal metabolism to the $+4^{\circ} \mathrm{C}$ treatment is striking. There is an obvious large component of inter individual variance for time 0 measurements likely indicative of the handling stress in collecting and establishing the experimental cultures. This variance is essentially masking what a true mean for the field populations could be, and during the experimental time course, individuals in each treatment settle down in terms of metabolic variance. The equivalency in both respiration and CS between $+4^{\circ} \mathrm{C}$ and $-1.5^{\circ} \mathrm{C}$ after 4 weeks is the main result we are interested in pursuing: are rates equivalent because warmer water temperatures have no effect on metabolism in this worm, or are rates equivalent because worms are biochemically acclimated in some fashion?

As a first step to assess acclimation, we wanted to know if there was some measurement at a molecular level that we could make to ascertain whether or not these worms $\left(-1.5^{\circ} \mathrm{C}\right.$ vs. $+4^{\circ} \mathrm{C}$ ) were different in any way that might result in different 


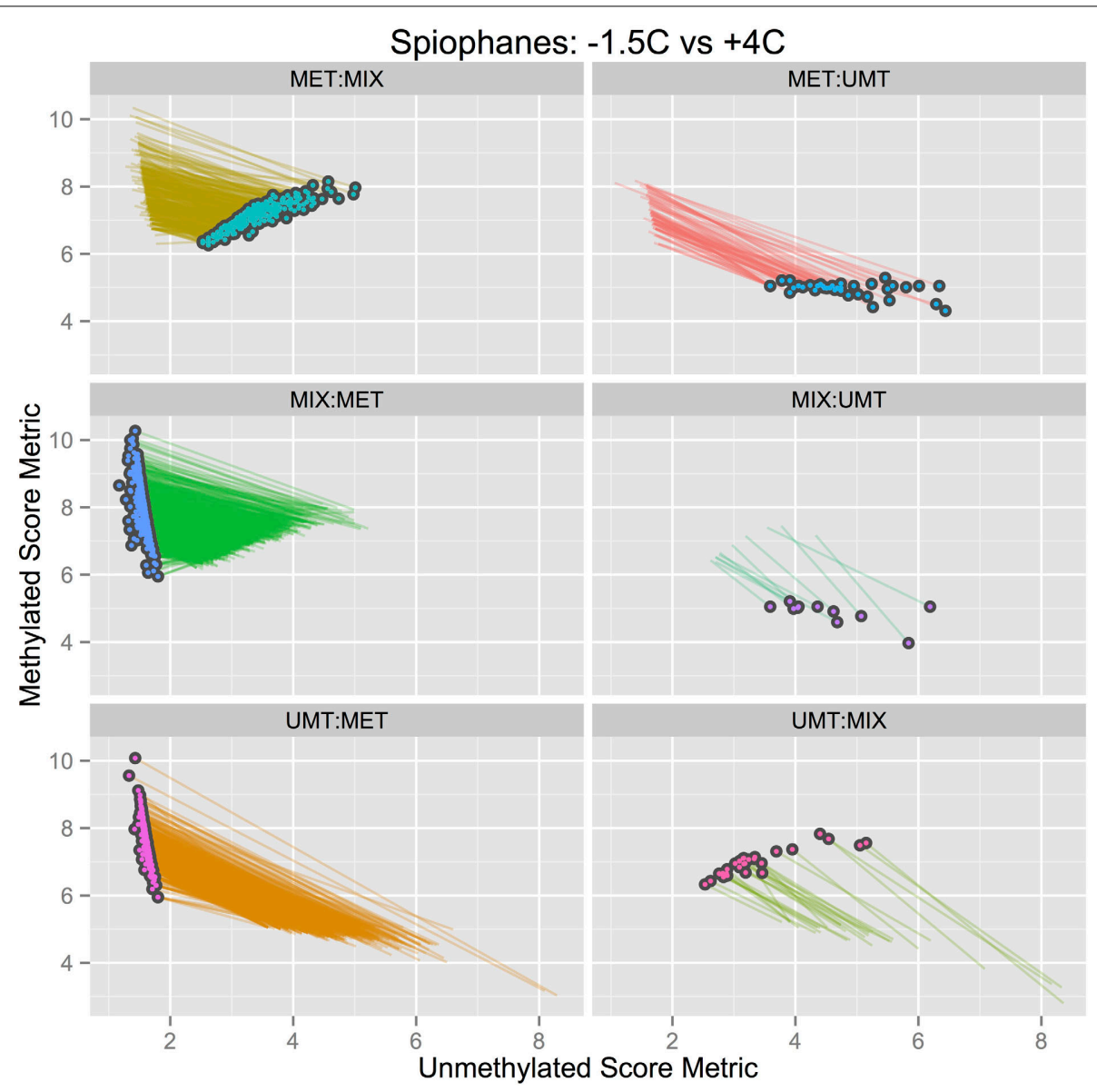

FIGURE 5 | Total methylation dynamics. Data for each CpG site in

Figures 3, 4 are now linked by a line and separated into six shifts (each panel) to reveal the pattern of shifts identified in the experiment. Each point on the plot represents a single $\mathrm{CpG}$ site that has evidenced a change in methylation state during the experiment ( $n=3067$ matched $\mathrm{CpG}$ sites). The circle symbols plot the quantitative state in the $+4^{\circ} \mathrm{C}$ treatment while the line extending from each circle connects to the methylation state of the same $\mathrm{CpG}$ site in the comparative $-1.5^{\circ} \mathrm{C}$ control treatment.
Table 2 | Directional methylation changes.

\begin{tabular}{lcc}
\hline $\mathbf{C p G} @ \mathbf{- \mathbf { 1 . 5 } ^ { \circ } \mathbf { C }}$ & $\mathbf{C p G} @ \mathbf{+ 4}^{\circ} \mathbf{C}$ & Observed counts \\
\hline MET & MIX & 326 \\
MET & UMT & 73 \\
MIX & MET & 1,742 \\
MIX & UMT & 11 \\
UMT & MET & 886 \\
UMT & MIX & 28 \\
\hline
\end{tabular}

These values are the number of points in each panel plot in Figure 5.

metabolic activities while maintaining equivalent metabolic costs (i.e., oxygen consumption rate as an index of ATP turnover). Here, we focused our first efforts on DNA methylation as potential evidence for regulatory shifts that could possibly differentiate metabolic/biochemical activities between temperature treatments.

\subsection{BIOINFORMATICS}

The analysis approach we have developed is similar to the strategy presented in Jelinek et al. (2012), where methyl-sensitive endo-restriction nucleases are utilized to digest gDNA during preparation for NGS sequencing. During sequence read processing and assembly the restriction sites are reconstructed computationally and quantitative metrics can be derived to describe restriction digest activity at individual $\mathrm{CpG}$ methylation sites.

Our results have been produced by a novel bioinformatic software platform guiding sequence data processing decisions and calculations from the QC filter of the raw sequence read files to the downstream generation of quantitative graphs and analyses (see Disclosure note). There are two important, novel facets of our approach to epigenomic profiling: (a) the analysis can detect mixed states of methylation prominence at individual CpG sites; and (b) the analysis utilizes two proprietary informatic metrics, both of which are continuous variables and not discrete binary "yes/no" classifications. These variable metrics allow us to quantitatively score methylation states relative to $(\mathrm{x}, \mathrm{y})$ positions on a 2D plane.

(a) Mixed Methylation States: Any tissue sample consists of a population of cells (100's of thousands). All genome copies present in a sample will not be $100 \%$ identical in terms of 


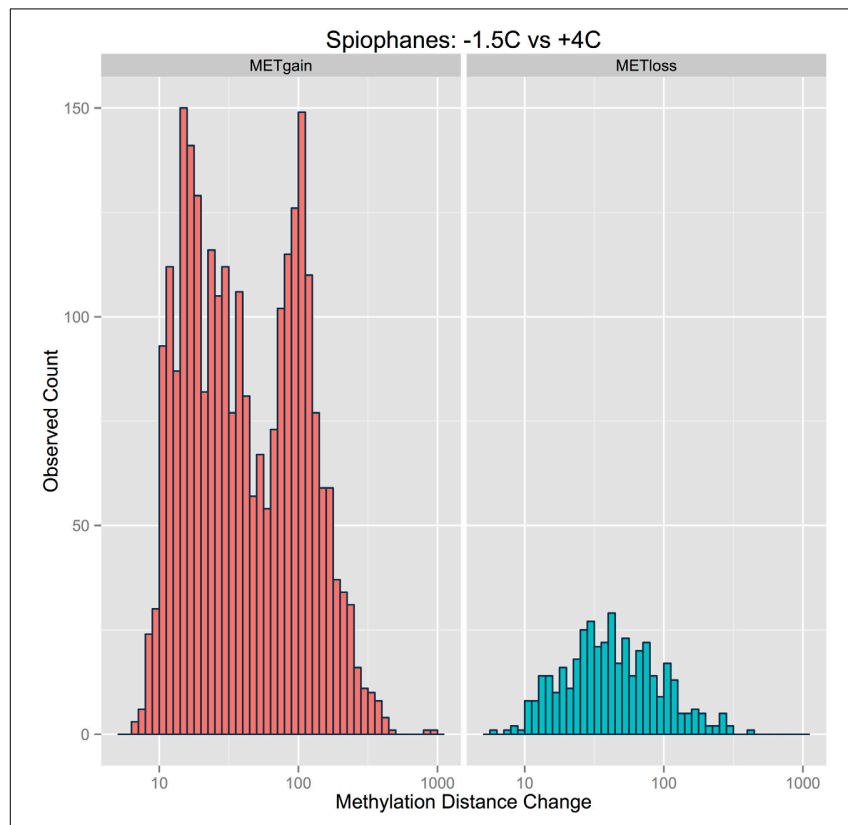

FIGURE 6 | Distributions of the magnitude of the methylation changes for each CpG site divided into gain and loss components.

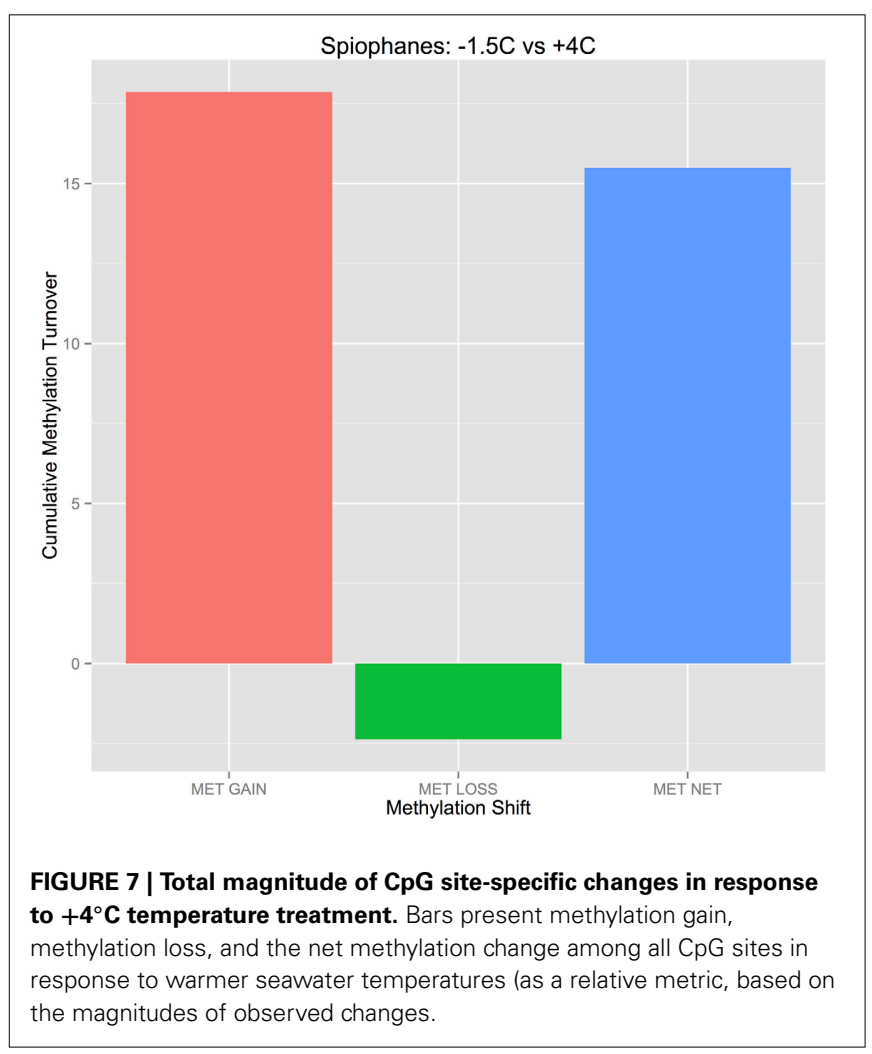

site-specific $\mathrm{CpG}$ methylation. The unique approach developed here can identify mixed patterns of methylation state (where some fraction of $\mathrm{CpG}(\mathrm{i})$ is methylated and some are unmethylated). This is critical when comparing samples for differences in methylation patterns because $\mathrm{CpG}(\mathrm{i})$ sites that are differentially methylated between two samples are likely the informative sites that account for differences in cellular function. It is these changing or dynamic $\mathrm{CpG}$ sites that are essential to identify and describe in terms of their potential contribution to altering functional biochemical and physiological phenotypes.

(b) Quantitative Metrics: The spatial location on a 2D plane using two continuous, quantitative metrics, allows us to readily calculate a strength vector for quantifying the magnitude of CpGspecific methylation shifts. Figure 5 presents a comparative plot using a line to connect the $\mathrm{CpG}(\mathrm{i})$ states between the $-1.5^{\circ} \mathrm{C}$ and $+4^{\circ} \mathrm{C}$ treatments. A distance metric for this separation between points serves as an intuitive metric for the magnitude of any given methylation change. This quantitative discrimination is critical for ranking the relevance of total changes observed.

\subsection{DNA METHYLATION}

After 4 weeks of living at $+4^{\circ} \mathrm{C}$, S. tcherniai exhibit large shifts in DNA methylation patterns in direct comparison to control worms maintained at $-1.5^{\circ} \mathrm{C}$. Overall, there is a predominance of methylation gains at specific $\mathrm{CpG}$ sites. This is clear in the aggregate summary histogram in Figure 7, the methylation magnitude of gains and losses in Figure 6, and the single $\mathrm{CpG}$ tracking lines in Figure 5. The large numerical shift in the UMT to MET state (Figure 5, lower left panel) represents the archetypical, binary response that one tends to focus on when thinking about epigenetic shifts. Here, all CpG-site copies (gDNA sample has 100's thousands of genome copies from every cell in the sample) were unmethylated at day 28 in worms living at $-1.5^{\circ} \mathrm{C}$ while all corresponding $\mathrm{CpG}$-site copies in the $+4^{\circ} \mathrm{C}$ worms were fully methylated. It is easy to think of this as an on/off switch response.

The ability to score a $\mathrm{CpG}$ site as being fractionally methylated among gDNA copies in a sample opens up a new avenue for assessing DNA methylation responses to changing cellular conditions. By quantitatively distinguishing a "mixed" population of copies of one CpG site, we can begin to identify dynamic, non-binary, continuous-response reactions in DNA methylation intensity or density (average change per copy). Looking at the MET:MIX and MIX:MET panels in Figure 5, we see a dynamic balance between CpG sites that switch between states of $100 \%$ fully methylated across all gDNA copies to $50 \%$ mixed states. We can conclude that these CpG sites are dynamic and that a 50\% methylation position represents a response to shift in some cells, but not others, resulting in a mixed population of $\mathrm{CpG}$ specific states within a gDNA extract.

This differential or dynamic response raises the obvious question of how cell-type may impact gDNA methylation profiles when whole organisms are sampled. Tissue heterogeneity is not a new problem to genomic profiling, where even needle biopsies are large enough to include cell to cell variance in genome states. It is likely that the mixed population measurements result from gDNA originating from different tissues within an adult worm. Here, it is important to note that we achieve a large degree of numerical differentiation with our analysis and that within a group designation, such as MET, the $y$-axis methylated score metric still ranges almost 2-fold, from 6 to 10 metric units. We are pursuing further refinements to assess if this score range may be further used in future analyses to classify gDNA copies into different cell types. 


\section{CONCLUSION}

We have performed an epigenetic profiling analysis on a marine invertebrate that has no prior molecular genomic resources available. We have shown that DNA methylation responses to small changes in temperature in this Antarctic worm are dominated by gains in $5 \mathrm{mC}$ abundance. However, even though the result is informative, the problem now is that this information would be more useful and insightful if we could map those CpG shifts back to defined gene loci. We've attempted to utilize the polychaete Capitella teleta genome resources available (Joint Genome Institute, PI E. Seaver). Unfortunately, work to derive a genome fragment assembly for $S$. tcherniai is still in progress. We are currently sequencing deeper in order to assemble larger contigs covering sufficient protein coding domains so that those contigs can be confidently mapped to $C$. teleta loci. At this point, we know the next step to putting this response in a functional context is going to require more gDNA work. This is the challenge of working with non-model organisms.

An essential component of the definition of any living system is the environment that surrounds it, and to which the organism is intimately connected. We could describe the polychaete $S$. tcherniai as an open system constantly engaged in complex interactions with its surroundings. The separation of animal from environment is tenuous because of the perpetual exchange of physical, chemical, mechanical, and biological information between them (Alberghina et al., 2009). Many of these external forces can initiate internal, cellular chromatin remodeling resulting in an epigenome that is continuously modified in response to environmental factors, like food availability or physiological stress (Vinci, 2011).

As more epigenetic work shifts from model systems to focusing on organisms that live in natural environments, we are beginning to understand the tight associations that can exist between an organism's epigenome and it's habitat (Elango et al., 2009; Gavery and Roberts, 2010; Okamura et al., 2011; Gmezdiaz et al., 2012; Falckenhayn et al., 2013; Glastad et al., 2013; Wang et al., 2013). In this paper we have shown that metabolic rates in S. tcherniai return to normal within 4 weeks following a high-temperature stress, and that shifting patterns of DNA methylation arise during this time course. Work continues to identify the degree to which those methylation shifts may play a role in the regulation of energy metabolism in this Antarctic polychaete.

\section{FUNDING}

This work was made possible through a grant from the National Science Foundation to Adam G. Marsh (Office of Polar Programs, \#0944557), and with National Science Foundation support to Adam G. Marsh for the commercial development of the software (Innovation Corps program, \#1355306).

\section{ACKNOWLEDGMENTS}

We thank Dr. Stephanie Guida, Mr. Michael League, and Dr. Stacy Kim for their efforts while working at McMurdo Station, Antarctica. We also acknowledge the tremendous support provided by the United States Antarctic Program and Raytheon Polar Services.

\section{REFERENCES}

Alberghina, L., Hoefer, T., and Vanoni, M. (2009). Molecular networks and systemlevel properties. J. Biotechnol. 144, 224-233. doi: 10.1016/j.jbiotec.2009.07.009

Angers, B., Castonguay, E., and Massicotte, R. (2010). Environmentally induced phenotypes and DNA methylation: how to deal with unpredictable conditions until the next generation and after. Mol. Ecol. 19, 1283-1295. doi: 10.1111/j.1365-294X.2010.04580.x

Blake, J. (1983). Polychaetes of the family spionidae from south america, Antarctica and adjacent seas and islands. Biol. Antarct. Seas XIV (Antarctic Research Series) 39, 205-288. doi: 10.1029/AR039p0205

Blake, J. A., and Arnofsky, P. L. (1999). Reproduction and larval development of the spioniform polychaeta with application to systematics and phylogeny. Hydrobiologia 402, 57-106. doi: 10.1023/A:1003784324125

Boyko, A., and Kovalchuk, I. (2008). Epigenetic control of plant stress response. Environ. Mol. Mutagen. 49, 61-72. cited By (since 1996) 79. doi: 10.1002/em.20347

Conlan, K., Kim, S., Lenihan, H., and Oliver, J. (2004). Benthic changes during 10 years of organic enrichment by momurdo station, Antarctica. Mar. Pollut. Bull. 49, 43-60. doi: 10.1016/j.marpolbul.2004.01.007

Conlan, K. E., Kim, S. L., Thurber, A. R., and Hendrycks, E. (2010). Benthic changes at mcmurdo station, Antarctica following local sewage treatment and regional iceberg-mediated productivity decline. Mar. Pollut. Bull. 60, 419-432. doi: 10.1016/j.marpolbul.2009.10.009

Correia, B., Valledor, L., Meijon, M., Rodriguez, J., Dias, M., Santos, C., et al. (2013). Is the interplay between epigenetic markers related to the acclimation of cork oak plants to high temperatures? PLoS ONE 8:e53543. doi: 10.1371/journal.pone.0053543

Cowart, D. A., Guida, S., Shah, S., and Marsh, A. G. (2011). Effects of ag nanoparticles on survival and oxygen consumption of zebra fish embryos, Danio rerio. J. Environ. Sci. Health Part A 46, 1122-1128. doi: 10.1080/10934529.2011. 590726

Doney, S. C., Ruckelshaus, M., Duffy, J. E., Barry, J. P., Chan, F., English, C. A., et al. (2012). "Climate change impacts on marine ecosystems," in Annual Review of Marine Science, Vol. 4, eds C. A. Carlson and S. J. Giovannoni (Palo Alto, CA: Annual Reviews), 11-37.

Elango, N., Hunt, B. G., Goodisman, M. A. D., and Yi, S. V. (2009). DNA methylation is widespread and associated with differential gene expression in castes of the honeybee, Apis mellifera. Proc. Natl. Acad. Sci. U.S.A. 106, 11206-11211. doi: 10.1073/pnas.0900301106

Falckenhayn, C., Boerjan, B., Raddatz, G., Frohme, M., Schoofs, L., and Lyko, F. (2013). Characterization of genome methylation patterns in the desert locust Schistocerca gregaria. J. Exp. Biol. 216, 1423-1429. doi: 10.1242/jeb.080754

Faloona, G., and Srere, P. A. (1969). Escherichia coli citrate synthase: purification and effect of potassium on some properties. Biochemistry 8, 4497-4503. doi: 10.1021/bi00839a041

Feil, R. (2006). Environmental and nutritional effects on the epigenetic regulation of genes. Mutat. Res. 600, 46-57. doi: 10.1016/j.mrfmmm.2006.05.029

Fields, P. A., Strothers, C. M., and Mitchell, M. A. (2008). Function of muscle lactate dehydrogenase and citrate synthase of the galapagos marine iguana, amblyrhynchus cristatus, in relation to temperature. Comp. Biochem. Physiol. B Biochem. Mol. Biol. 150, 62-73. doi: 10.1016/j.cbpb.2008. 01.008

Gavery, M. R., and Roberts, S. B. (2010). DNA methylation patterns provide insight into epigenetic regulation in the Pacific oyster (Crassostrea gigas). BMC Genomics 11:483. doi: 10.1186/1471-2164-11-483

Glastad, K. M., Hunt, B. G., and Goodisman, M. A. D. (2013). Evidence of a conserved functional role for DNA methylation in termites. Insect Mol. Biol. 22, 143-154. doi: 10.1111/imb.12010

Glazer, B., Marsh, A., Stierhoff, K., and Luther, G. (2004). The dynamic response of optical oxygen sensors and voltammetric electrodes to temporal changes in dissolved oxygen concentrations. Anal. Chim. Acta 518, 93-100. doi: 10.1016/j.aca.2004.05.040

Gmez-diaz, E., Jorda, M., Peinado, M. A., and Rivero, A. (2012). Epigenetics of host-pathogen interactions: the road ahead and the road behind. PLoS Pathog. 8:e1003007. doi: 10.1371/journal.ppat. 1003007

Grube, A. (1860). Beschreibung neuer oder wenig bekannter beschreibung neuer oder wenig bekannter anneliden. Arch. Naturgesch. 26, 71-118.

Ho, D. H., and Burggren, W. W. (2010). Epigenetics and transgenerational transfer: a physiological perspective. J. Exp. Biol. 213, 3-16. doi: 10.1242/jeb.019752 
Hunt, B., Hoefling, K., and Cheng, C. H. C. (2003). Annual warming episodes in seawater temperatures in momurdo sound in relationship to endogenous ice in notothenioid fish. Antarct. Sci. 15, 333-338. doi: 10.1017/S095410 2003001342

Jaenisch, R., and Bird, A. (2003). Epigenetic regulation of gene expression: how the genome integrates intrinsic and environmental signals. Nat. Genet. 33, 245-254. doi: $10.1038 / \mathrm{ng} 1089$

Jelinek, J., Liang, S., Lu, Y., He, R., Ramagli, L. S., Shpall, E. J., et al. (2012). Conserved dna methylation patterns in healthy blood cells and extensive changes in leukemia measured by a new quantitative technique. Epigenetics 7 , 1368-1378. doi: 10.4161/epi.22552

Kim, S., Hammerstom, K. K., Conlan, K. E., and Thurber, A. R. (2010). Polar ecosystem dynamics: recovery of communities from organic enrichment in mcmurdo sound, Antarctica. Integr. Compa. Biol. 50, 1031-1040. doi: 10.1093/icb/icq058 (Annual Meeting of the Society-for-Integrative-andComparative-Biology, Seattle, WA, Jan 03-07, 2010).

Lenihan, H., and Oliver, J. (1995). Anthropogenic and natural disturbances to marine benthic communities in Antarctica. Ecol. Appl. 5, 311-326. doi: $10.2307 / 1942024$

Marsh, A. G., Gremare, A., and Tenore, K. (1989). Effect of food type and ration on growth of juvenile Capitella sp-i (annelida, polychaeta) - macronutrients and micronutrients. Mar. Biol. 102, 519-527. doi: 10.1007/BF00438354

Marsh, A. G., Leong, P. K. K., and Manahan, D. T. (1999). Energy metabolism during embryonic development and larval growth of an Antarctic sea urchin. J. Exp. Biol. 202, 2041-2050.

Moline, M. A., Karnovsky, N. J., Brown, Z., Divoky, G. J., Frazer, T. K., Jacoby, C. A., et al. (2008). "High latitude changes in ice dynamics and their impact on polar marine ecosystems," in Year in Ecology and Conservation Biology 2008. Annals of the New York academy of sciences. Vol. 1134, eds R. S. Ostfeld and W. H Schlesinger (Hoboken, NJ: John Wiley \& Sons, Inc.), 267-319.

Okamura, K., Yamashita, R., Takimoto, N., Nishitsuji, K., Suzuki, Y., Kusakabe, T. G., et al. (2011). Profiling ascidian promoters as the primordial type of vertebrate promoter. BMC Genomics 12:3. doi: 10.1186/1471-2164-12-S3-S7 1st ISCB Asia joint conference on computational biology (InCoB/ISCB-Asia)/10th international conference on bioinformatics, Kuala Lumpur, Malaysia, Nov 30-Dec 02, 2011.

Oliver, J. S., and Slattery, P. N. (1985). Effects of crustacean predators on species composition and population structure of soft-bodied infauna from mcmurdo sound, Antarctica. Ophelia 24, 155-175. doi: 10.1080/00785326.1985.10429725

Pace, D. A., Marsh, A. G., Leong, P. K., Green, A. J., Hedgecock, D., and Manahan, D. T. (2006). Physiological bases of genetically determined variation in growth of marine invertebrate larvae: a study of growth heterosis in the bivalve crassostrea gigas. J. Exp. Mar. Biol. Ecol. 335, 188-209. doi: 10.1016/j.jembe.2006.03.005
Pecinka, A., Dinh, H. Q., Baubec, T., Rosa, M., Lettner, N., and Scheid, O. M. (2010). Epigenetic regulation of repetitive elements is attenuated by prolonged heat stress in arabidopsis. Plant Cell 22, 3118-3129. doi: 10.1105/tpc. 110.078493

Richard, J., Morley, S. A., Thorne, M. A. S., and Peck, L. S. (2012). Estimating longterm survival temperatures at the assemblage level in the marine environment: towards macrophysiology. PLoS ONE 7:4. doi: 10.1371/journal.pone.0034655

Schofield, O., Ducklow, H. W., Martinson, D. G., Meredith, M. P., Moline, M. A., and Fraser, W. R. (2010). How do polar marine ecosystems respond to rapid climate change? Science 328, 1520-1523. doi: 10.1126/science.1185779

Szela, T., and Marsh, A. (2005). Microtiter plate, optode respirometry, and interindividual variance in metabolic rates among nauplii of artemia sp. Mar. Ecol. 296, 281-289. doi: 10.3354/meps296281

Varriale, A., and Bernardi, G. (2006a). Dna methylation and body temperature in fishes. Gene 385, 111-121. doi: 10.1016/j.gene.2006.05.031

Varriale, A., and Bernardi, G. (2006b). Dna methylation in reptiles. Gene 385, 122-127. doi: 10.1016/j.gene.2006.05.034

Vinci, M. C. (2011). Sensing the environment: epigenetic regulation of gene expression. Phys. Chem. Biophys. S3:001. doi: 10.4172/2161-0398.S3-001

Wang, X., Wheeler, D., Avery, A., Rago, A., Choi, J.-H., Colbourne, J. K., et al. (2013). Function and evolution of DNA methylation in nasonia vitripennis. PLoS Genet. 9:e1003872. doi: 10.1371/journal.pgen.1003872

Wolffe, A., and Matzke, M. (1999). Epigenetics: regulation through repression. Science 286, 481-486. doi: 10.1126/science.286.5439.481

Conflict of Interest Statement: The software platform designed for processing DNA methylation profiles from NGS sequence data is proprietary and covered by a provisional patent application filed by the University of Delaware, which is currently being considered for an exclusive license agreement by a company co-founded by Adam G. Marsh. These activities are supported by an Innovation Corps Grant from the National Science Foundation as noted below.

Received: 22 November 2013; accepted: 14 April 2014; published online: 05 May 2014. Citation: Marsh AG and Pasqualone AA (2014) DNA methylation and temperature stress in an Antarctic polychaete, Spiophanes tcherniai. Front. Physiol. 5:173. doi: 10.3389/fphys.2014.00173

This article was submitted to Invertebrate Physiology, a section of the journal Frontiers in Physiology.

Copyright (c) 2014 Marsh and Pasqualone. This is an open-access article distributed under the terms of the Creative Commons Attribution License (CC BY). The use, distribution or reproduction in other forums is permitted, provided the original author(s) or licensor are credited and that the original publication in this journal is cited, in accordance with accepted academic practice. No use, distribution or reproduction is permitted which does not comply with these terms. 